\section{Por ora, menos que a metade: a lei de drogas brasileira}

\section{For now, less than half: the Brazilian drug law}

Resenha de: CAMPOS, Marcelo da Silveira. (2019), Pela Metade: a lei de drogas no Brasil, Editora Annablume, SP.

\section{Beatriz Brandáo \\ E-mail: brandao.beatrizm@gmail.com}

(1) Pós doutoranda em Sociologia pela Universidade de São Paulo, SP, Brasil.

DOI: $10.1590 / 3610516 / 2020$

"A história das drogas é, antes de tudo, a história de suas regulações" (CARNEIRO, 2018, p. 19). Essa afirmação está minuciosamente apresentada na obra de Marcelo da Silveira Campos, que se inclui dentre as maiores e mais completas pesquisas sobre a lei de drogas ${ }^{1}$, com destaque para seu fôlego intelectual, ineditismo metodológico, condução sociológica e jurídica e embasamento teórico. Uma das originalidades do livro de Campos é apresentar uma pesquisa que vai desde a formulação de uma lei, passando pelas principais discussóes no Congresso Nacional, até a sua implementaçáo, e como ela é absorvida e acionada pelo sistema de justiça criminal e pela Polícia Militar. Através de um estudo por dentro da política, vemos a frase do título "pela metade" - uma referência a um copo cheio de punição e vazio do dispositivo médico preventivo - tomar sentido no decorrer de sua narrativa. Um verdadeiro mergulho na lei de drogas de 2006 nos levou à compreensão do seu interior, de seu processo e de suas possíveis evacuações.

A questão do livro está expressa no argumento de que a mudança substancial que a lei trouxe o aumento da pena mínima, para o traficante de drogas $^{2}$, e a retirada da pena aflitiva de prisão, para o usuário -, na verdade, fortaleceu o encarceramento no país. Tendo como cenário de pesquisa a cidade de Sáo Paulo, maior metrópole e epicentro de problemas relacionados à política sobre drogas, essa temática foi articulada de várias formas, ao longo do livro. Marcelo
Campos responde ao que denominou dispositivo médico-criminal, com métodos e argumentos teóricos diferentes, ao longo de cinco capítulos, que vão desde o acompanhamento das plenárias pré-aprovação da lei quando ainda se tratava de um Projeto de Lei (PL), até o estudo de caso único, passando pelo método de séries temporais e regressão binária logística ${ }^{3}$, terminando com entrevistas de importantes personagens atuantes em esferas diferentes e centrais dessa discussão. Além disso, a obra nos apresenta o cenário do Canadá, com comparaçóes que atravessam consistências e inconsistências nas diferenças entre modelos adotados internacionalmente. Pela metade nos permite aceder a muitas gramáticas, repertórios e formas de apresentar uma questão, indo do macro ao micro, numa análise horizontal e aprofundada.

No Capítulo I, temos acesso aos principais argumentos dos deputados e senadores, revelando a lei como construção de um empreendimento moral. O que o leitor vai encontrar é o processo de consecução, pensamento e idealizaçáo de uma lei, e os mecanismos que a tornam possível. Não tínhamos uma lei das drogas desde $1976^{4}$, cujo regimento nos indicava e impulsionava para a necessidade de uma nova força disruptiva, a qual se oficializou em 23/08/2006, nos idos do Governo do entáo presidente Lula ${ }^{5}$, sob a forma da lei de drogas. Sua novidade, na esteira legal no âmbito das drogas no Brasil, é a de que ela oferecia medidas de arrefecimento para usuários de drogas, tratando-os como instrumentos de cuidado e não mais de punição, com a responsabilidade recaindo sobre o sistema de saúde, e eles sendo mais detidamente vistos e tratados sob a ótica da redução de danos (RD).

O pretenso arrojamento da lei se dava em resposta a movimentos internacionais que impulsionavam algumas transiçôes: um enfoque menor nos perigos e maior no uso racional; na redução de políticas repressivas e punitivas; e no tratamento pragmático operado em muitos países pela RD. Por outro lado, para que não parecesse que o paradigma proibicionista deixava de ser sedimentado, a pena de prisão para os traficantes agiu como resposta estatal, dando ares de endurecimento à lei. O recrudescimento na área do mercado e varejo de drogas atuava como medida compensatória, em que a retirada da pena de prisão 
para o usuário não fizesse parecer que estavam atenuando a postura e ação de combate às drogas, e assim conseguisse responder "ao clamor da sociedade brasileira"

Acontece que, como o autor aponta, há no Brasil a coexistência histórica entre uma lógica universal e uma lógica hierarquizante, que engendrou o encarceramento massivo a partir da mudança legal. Sendo este o argumento central do livro, verificamos como o processo ocorreu e a quem inferiu mudanças, no percurso da rua para a cadeia. A questão é que o discurso absorvido pela narrativa da guerra às drogas, apropriado ao longo de 50 anos $^{7}$, não poderia ser desterritorializado em seu poder e foi esclarecido pelo discurso de média de conhecimento.

Explicando detalhadamente tal expressão, a Comissão Mista de Segurança Pública ${ }^{8}$ apresentou, em 2002, o PL 115/2002, do Senado Federal, em que os parlamentares argumentavam que uma mudança era necessária, já que a lei anterior não diferenciava objetivamente uso/porte/tráfico de drogas, sendo preciso outra lei para dirimir negociaçóes ilícitas entre traficantes, usuários e policiais. Dessa Comissão, faziam parte parlamentares de partidos de linhas políticas distintas, que buscavam a criação do Sistema Nacional Antidrogas (SISNAD), alcançando-o por uma "média de conhecimento" que ultrapassava as suas diferenças, fato revelador que, embora com mudanças de posicionamentos ideológicos acerca da descriminalização das drogas, o que a lei propunha alcançou uma racionalidade comum entre os pares, independentemente da corrente política a que eram afiliados.

$\mathrm{O}$ contexto que embasou tais argumentos, e que não pode ser deixado de lado, foi um episódio: a chamada onda de sequestros em São Paulo, deflagrada no início dos anos 2000. Tal contexto é definidor para fortificar e calcificar visóes de mundo, a referida onda indica que eventos e episódios redesenham políticas públicas, de modo não acidental, mas sim, agem como oportunidade propícia para a ratificação do argumento, com materialidade para sustentar os discursos moralizantes e para comprovar e executar açóes em sua prática.

Os debates nas plenárias, referentes aos diferentes papéis entre aquele que apenas consome drogas e aquele que comercializa, ocorreram entre mecanismos de coerção e prevenção. É importante frisar que a descriminalização do uso/porte de drogas não era um objetivo a ser atingido, e sim apenas o fim da pena de prisão para o uso de drogas ${ }^{9}$. O fato problematizado foi que a decisão em fazer da lei um dispositivo médico-criminal adensava a existência de controle estatal em ambos os casos, seja pela saúde ou pela segurança, o que nos impóe refletir sobre os modos pelos quais o poder investe sujeitos por meio de racionalidades políticas.

Resumindo, a prática que vinha sendo feita até então estava em concordância com os tratados e convençóes que inscreveram o Brasil como signatário do pensamento proibicionista, que dava sentido praticamente linear à história legal. Era necessário compreender o sistema criminal pelos atravessamentos sociológicos, ao ligar crime, incriminação, ação policial, sistema carcerário, poder jurídico e política de alto escalão. Por que uma nova lei de drogas? O que nos encaminhava para tal mudança? Que modificaçóes no tecido social brasileiro nos levavam a reaver nossos equipamentos políticos e mobilizar os três poderes para tais transformaçóes? E ainda, quais foram os contrastes substantivos que a lei trouxe, para ser chamada de nova? São essas - e mais - perguntas que o autor responde ao longo do primeiro capítulo, não apenas com suas análises e interpretaçôes, mas também usando as próprias palavras dos deputados $\mathrm{e}$ senadores em seus esforços de debate, afastamento e conciliação na arena pública do Congresso Nacional, buscando uma "média de conhecimento da Casa". Em que se constituía essa aritmética percentual média, que resultou, na verdade, em aprofundamento de incriminaçóes com base no julgamento moral que já vinha se repetindo há várias décadas?

Uma das perspectivas propostas é se pensar por que os discursos acionados nas plenárias são tidos como verdadeiros e quais são os efeitos do reforço dos binarismos legais: usuário/traficante, repressão/redução de danos, assistência social/saúde, prisão/clínica. Complexidades como estas foram respondidas, na letra da lei, por meio de uma matemática penal em que os binarismos foram ratificados e espelhados em duas metades: a da dimensão punitiva e criminalizadora e a médico-social. 
Mas como foram, na prática, os efeitos desta mudança? No Capítulo 2 do livro, encontramos respostas quantitativas que indicam que o aumento do encarceramento foi intensificado após a lei de drogas. Para responder como o sistema de justiça criminal incorporou o novo dispositivo de drogas médico-criminal, o livro nos dá acesso aos dados ${ }^{10}$ sobre criminalização por comércio e uso de drogas, entre os anos de 2004 e 2009, em São Paulo, no bairro de Santa Cecília e município de Itaquera ${ }^{11}$. O fato é que o aprisionamento por drogas no Brasil teve uma súbita crescente: tínhamos $13 \%$ do total de presos e presas por narcotráfico, em 2005, e, em 2013 , esse número subiu para $27,2 \%$. No quadro geral, tivemos uma taxa de encarceramento que triplicou em 16 anos $^{12}$.

As implicaçóes reversas ao esperado pelos formuladores do dispositivo sáo a chave para o questionamento sobre a posição social dos indivíduos incriminados. Informaçóes sobre idade, gênero, escolaridade e ocupação desvelam quais escolhas institucionais e morais fundamentam o reconhecimento de um sujeito, como traficante ou usuário de drogas. A condiçãao social do indivíduo náo pode ser negligenciada nas práticas da justiça criminal e um dos pontos cruciais trazidos em pauta, no capítulo 2 do livro, é o aumento do encarceramento feminino por questóes referentes às drogas. As hipóteses levantadas pelo autor repousam, primeiro, no elevado número de mulheres que transportam substâncias ilícitas por seus companheiros, pois, em seus depoimentos nos autos de prisão, explicavam que os maridos seriam ameaçados de morte na unidade, caso elas não levassem a droga. Portanto, a relaçáo mecânica, que comumente é feita entre relaçóes amorosas e a entrada de mulheres no tráfico, é habilmente desconstruída e analisada no capítulo.

Existem muitos casos de referência à ligaçáo entre a entrada no tráfico e os relacionamentos amorosos; porém, nos depoimentos, as pesquisadas apontam que as motivações são, em primeiro lugar, por necessidade financeira, $28 \%$, enquanto apenas $8 \%$ citam a influência do companheiro. Sobre as dificuldades financeiras, os apontamentos se ancoram na maternidade, e em suas responsabilidades pelos filhos serem cuidados sem nenhum auxílio do pai.
A entrada para o crime, como meio de sobrevivência e aumento de renda, se dá, majoritariamente, entre mulheres jovens, de baixa renda, em geral mães presas provisórias por crimes de tráfico, perfil de mulheres em situação prisional no Brasil. Para exemplificar tais dados, Marcelo Campos nos apresenta o caso de Bia, que, quando tinha 18 anos, , quando começou seu envolvimento com o comércio de drogas na faculdade, e se destaca na posição de mulheres vistas como autoras no tráfico, o que Joan Scott (1995) defende como uma das definiçóes de gênero: ênfase no aspecto relacional das definiçóes normativas de feminilidade.

A disjunçáo pretendida - a descarcerização do usuário de drogas - pelas mudanças no interior da lei de drogas também não foi alcançada, porque, como nos conduz o autor, a instituição de justiça criminal rejeita qualquer ideia com potencial de inovação. A falta de critérios objetivos ${ }^{13}$ faz com que haja usuários sendo incriminados como traficantes, devido à discricionariedade policial e de operadores do sistema de justiça criminal. Desde o advento da lei, as chances de um usuário ser considerado como traficante em Sáo Paulo aumentou quatro vezes. A segunda maior forma de incriminação, por fator estatístico, recai entre aqueles com menor escolaridade (analfabetos e ensino fundamental incompleto), que possuem 3,6 mais chances de serem considerados traficantes. E, em terceiro lugar, caso o suspeito more num bairro periférico, terá duas vezes mais possibilidades de ser considerado traficante, e não usuário.

Fica evidenciado, pelos números apresentados, que a organização do sistema de justiça criminal atua no processo de sujeiçáo criminal ${ }^{14}$, que reverbera desde a ação policial até a decisão judicial. Nos capítulos 1 e 2 , temos acesso à relação entre os três poderes, na regulação de açôes e decisóes do Legislativo, Judiciário e Executivo, e como o poder militar transita, estimula e ratifica certos preceitos e pensamentos que estáo instaurados em todas essas instâncias de poder ${ }^{15}$. Alguns fundamentos morais que regem as decisōes judiciais são ancorados, no Brasil, pelo modo Civil Law, que favorece o poder da acusaçáo policial, enquanto a Common Law, utilizado em outros países, possibilita o poder de barganha entre acusado e réu, a qual, na maioria dos casos, deve ser a acusação para 
provar a culpabilidade do réu ${ }^{16}$. Como conclusóes, temos que a lei de drogas intensificou a gestão dos ilegalismos, no sentido de Foucault (2006), e deixou mais evidenciada uma lógica de cidadania regulada (SANTOS, 1998).

A partir da metáfora do "copo", que, nestes dois capítulos, nos conduziu pelas teorias, em dados e análises, somos levados ao estudo de um caso único, no capítulo 3. Uma pessoa é condenada pelo juiz a três anos e quatro meses de reclusão por tráfico de drogas, sem antecedentes criminais, portando na boca 17 pedras de crack (4,25 gramas). Por meio de tópicos de reconstituição, interpretação e codificação, acessamos um vocabulário de motivos típicos das distinçóes entre usuários e comerciantes, utilizados pelo Judiciário a fim de conferir a pena. Eis o acontecimento narrado por policiais dos atos que se tornam autos: há uma quebra de rotina, porque policiais avistam o suspeito, na tentativa de abordagem, ele evade durante o enquadramento e uma pequena quantidade de droga é encontrada junto a uma quantia de $\mathrm{R} \$ 73,00$ e um telefone celular. Questionado sobre a origem da droga, ele diz que a vende e, assim, acontece a prisão.

É importante narrar o episódio exatamente como fizeram os policiais militares, pois ele será acionado reiteradamente pelo juiz para fazer prosseguir o julgamento. Isso porque, em $74 \%$ dos casos, os autos são baseados somente nos testemunhos dos policiais $\mathrm{da}$ abordagem, raramente apresentando outras versóes, nem mesmo a do próprio acusado. Ocorrem variaçóes subjetivas de julgamento sobre indivíduos, cuja incriminação pode antecipar a sua criminalização. Vemos, portanto, acusação que remonta à pobreza: não é possível que esse sujeito tenha um celular e $\mathrm{R} \$ 73,00$. O que temos é uma produção de verdades judiciárias na seleção do vocabulário de motivos válidos.

No capítulo 4, chegamos à realidade comparada entre Canadá e Brasil. O Canadá se organiza na política sobre drogas exatamente no reverso do Brasil, e pratica seriamente a abordagem da $\mathrm{RD}$, legalizando a maconha no fim de 2018, além de ter como forma jurídica a Common Law. Por outro lado, o país possui caráter repressivo quanto à posse e comércio de drogas, podendo chegar a penas perpétuas; isto é, a implementação do saber das práticas médicas preventivas coexiste com penas altíssimas para traficantes. O que mais nos diferencia do Canadá? Nossa moralização na decisão judicial. Lá, apesar de duras as sançóes, é rara a condenação a longas penas de prisão, apenas pela posse e pelo pequeno comércio; além disso, há critérios objetivos em que puniçóes são estabelecidas pela quantidade e tipo de droga.

O quarto e último capítulo fecha com três entrevistas esclarecedoras acerca de todos os temas tratados ao longo do livro, com referencial político, médico e jurídico, através do sociólogo e ex-presidente da República, Fernando Henrique Cardoso (FHC), do neurocientista, Sidarta Ribeiro, e da ex-vice procuradora geral da República, Ela Wiecko. Trazendo o cenário de legalização da cannabis no Uruguai, EUA e Canadá, ocorrida enquanto a pesquisa era realizada, o capítulo analisa como o tema da política de drogas impactou a agenda internacional. FHC aponta a discricionariedade que foi deslocada para o aparato policial, enquanto Sidarta Ribeiro destaca a visão binária em que se vitimiza o usuário, retirando sua autonomia, e se demoniza o traficante, perscrutando os possíveis matizes do assunto. Com Ela Wiecko, somos levados a pensar as práticas discricionárias do sistema de justiça criminal, que se intensificaram depois da lei de drogas.

Diante de Pela metade, resta-nos perguntar: o que faz a insistência em leis que repetem o mesmo equívoco? O que fazer quando seu corpo de legislação apenas ratifica o mesmo erro formado por anos? A lei de drogas náo é amorfa, e sim, reveladora de guerras que engendram a droga como substância centralizadora dos discursos punitivistas. O que nos faz, depois de tantos eventos, optarmos pela mesma cifra de valores? Pela metade decifra o que ficou do lado de dentro e de fora, e o que continua intocável na cartilha.

\section{Notas}

$1 \quad$ Lei 11.343 de 2006.

2 A pena mínima passa de três para cinco anos.

3 No capítulo 2, para apresentar os dados sobre a incriminaçáo por comércio e porte de drogas em São Paulo, o autor utiliza uma combinação entre metodologia estatística 
descritiva, cruzamentos, série temporal e regressão linear logística binária.

4 Lei 6.368 de 1976, expressando a adesão a toda uma normativa instituída pela narrativa internacional da "guerra às drogas", inserida num modelo políticocriminal de combate ao tráfico.

5 Sendo pertinente destacar que o projeto foi apresentado no Senado Federal, ainda no governo de Fernando Henrique Cardoso, em 2002, e debatido por quatro anos pelo Legislativo.

6 Uso o termo, em referência à fala numa plenária do deputado Paulo Pimenta (PT), que afirma que os "usuários devem ser vistos como pessoas que possuem vulnerabilidades de fundo individual e social e os traficantes deviam ser punidos de modo mais repressivo, atendendo ao clamor da sociedade brasileira”. Vemos aí a conformação de leis que atendam a esse clamor.

7 O paradigma proibicionista já existia, principalmente em sua prática. Refiro-me a uma "oficialização", a partir do discurso do presidente norte-americano Richard Nixon, em 17 de junho de 1971, nos EUA, que transformou a questão em problema de segurança e saúde internacionais, por meio de tratados.

8 Integrada por 20 senadores e 20 deputados titulares de partidos diversos, como PT, DEM, PSDB, PSB, PDT, PSL, entre outros.

9 Que ficou explícita no capítulo III da lei 11.343, de 2006: aumentar a pena para o tráfico de drogas, mantendo, ainda, a criminalizaçáo do porte para uso de drogas.

10 Dados fornecidos pela Secretaria de Segurança Pública do Estado de São Paulo.

11 A escolha dos locais de pesquisa teve o objetivo de comparar as criminalizaçóes feitas pela polícia no centro da capital paulista (77a Delegacia de Polícia de Santa Cecília, localizada na região central da cidade, a poucos metros da Cracolândia) e uma região na área periférica de São Paulo (33a Delegacia de Polícia de Itaquera).

12 Dados fornecidos pelo DEPEN (Departamento Penitenciário Nacional) do Ministério da Justiça.

13 Por exemplo, a quantidade e o tipo de drogas, que, como ficou comprovado na pesquisa de Marcelo Campos, não são fatores significativos para alguém ser incriminado como traficante ou usuário no Brasil. Segundo o autor, dentre as pessoas incriminadas, de um total de 799 registros que continham exatamente o tipo e quantidade de drogas, 404 ocorrências foram de 0,01 até 7 gramas de drogas por pessoa.
14 Atitude preventiva que pune aqueles que, mesmo sem cometer crime, são suspeitos potenciais de vir a cometêlos. (MISSE, 2010).

15 Cabendo ressaltar que a existência de uma população desviante é produto das regras criadas pela própria sociedade que a acusa. Esse pensamento é exposto no capítulo, na concepção teórica: taxas de comportamento desviante são produzidas pelo que um sistema social define, classifica e registra como tal (KITSUSE; CICOUREL, 1963); fontes e contextos geram e mantêm as definiçóes de desvio que produzem a populaçáo desviante.

16 Diferença esta, que fica mais evidenciada no Capítulo IV, na comparaçáo com o caso do Canadá.

\section{BIBLIOGRAFIA}

BRAGA, Ana Gabriela \& ANGOTTI, Bruna. (2014), Encarceramento de mulheres e exercicio da maternidade no Brasil atual: algumas reflexóes $e$ propostas. Disponível em:https://www.anpocs.com/ index.php/encontros/papers/38-encontro-anualda-anpocs/spg-1/spg02-1/9241-encarceramentode-mulheres-e-exercicio-da-maternidade-nobrasil-atual-algumas-reflexoes-e-propostas/file.

CARNEIRO, Henrique. (2018), Drogas: a história do proibicionismo, São Paulo, Autonomia Literária.

FOUCAULT, Michel. (2006), Gerir os ilegalismos. Entrevista a Roger Pol-Droit, gravada em janeiro de 1976, in Michel Foucault: entrevistas, Rio de Janeiro, Graal.

HELPES, Sintia Soares. (2014), Vidas em jogo: um estudo sobre mulheres envolvidas com o tráfico de drogas, São Paulo, IBCCRIM - Instituto Brasileiro de Ciências Criminais.

KITSUSE, J. \& CICOUREL, A. (1963). A note on the use of oficial statistics Social Problems. California, vol. 11(2): 23-38, nov.

MISSE, Michel. (2010), "Crime, sujeito e sujeiçáo criminal: aspectos de uma contribuição analítica sobre a categoria bandido”. Lua Nova, São Paulo, 79: 15-38.

SANTOS, Wanderley Guilhermedos. (1998). Décadas deespanto e uma apologia democrática, Rio de Janeiro, Editora Rocco.

SCOTT, Joan. (1995), Gênero: uma categoria útil de análise histórica. Educação e Realidade. Porto Alegre, 20(2): 71-99, jul-dez. 